\title{
Os mercados fazem bem à saúde? O caso do acesso aos cuidados
}

Are Markets Good for Your Health? The Case of Access to Healthcare

Les marchés sont-ils bons pour la santé? Le cas de l'accès aux soins

João Arriscado Nunes

\section{OpenEdition}

\section{Journals}

Edição electrónica

URL: http://journals.openedition.org/rccs/4427

DOI: $10.4000 /$ rccs. 4427

ISSN: 2182-7435

\section{Editora}

Centro de Estudos Sociais da Universidade de Coimbra

\section{Edição impressa}

Data de publição: 1 Dezembro 2011

Paginação: 137-153

ISSN: 0254-1106

\section{Refêrencia eletrónica}

João Arriscado Nunes, « Os mercados fazem bem à saúde? O caso do acesso aos cuidados », Revista Crítica de Ciências Sociais [Online], 95 | 2011, colocado online no dia 01 dezembro 2012, criado a 19 abril 2019. URL : http://journals.openedition.org/rccs/4427 ; DOI : 10.4000/rccs.4427 


\section{JOÃO ARRISCADO NUNES}

\section{Os mercados fazem bem à saúde? O caso do acesso aos cuidados*}

O atual contexto de crise que afeta, em particular, os países da União Europeia, tem ampliado o espaço favorável à promoção das políticas de saúde de inspiração neoliberal que postulam a subordinação deste setor à lógica do mercado, a privatização da gestão e prestação de serviços de saúde e o princípio do utilizador-pagador, associado a uma lógica assistencial para os que não podem pagar esses serviços. Dessa forma, seria alegadamente garantida a maior eficiência e sustentabilidade do sistema de saúde e a sua compatibilização com o imperativo da disciplina orçamental. Afirma-se a necessidade de uma reforma desse tipo para garantir a própria sobrevivência dos sistemas públicos de saúde, baseados na solidariedade e na redistribuição e garantindo acesso igual a todos os cidadãos aos cuidados de saúde. Mas essa reforma está associada à redução das opções políticas que se encontram na base dos modelos de prestação de cuidados de saúde a questões técnicas. São igualmente ignorados os efeitos observados, em estudos comparados, de diferentes modelos de prestação de cuidados sobre a saúde das populações.

Palavras-chave: acesso aos serviços de saúde; direito à saúde; políticas de saúde; saúde pública.

\section{Introdução}

$\mathrm{O}$ atual contexto de crise, que afeta, de maneira particularmente intensa, os países integrados na União Europeia, tem contribuído para conferir especial visibilidade à situação do Serviço Nacional de Saúde e à discussão sobre o seu presente e o seu futuro. Seria um equívoco, contudo, considerar essa discussão apenas como um efeito da crise e das suas implicações económicas, financeiras e políticas. Ela tem acompanhado, de facto, desde há quase

\footnotetext{
* Este texto é uma versão ampliada de uma comunicação apresentada no 3 . $^{\circ}$ Seminário CES sobre os Fundamentos da Economia, subordinado ao tema "Onde para o mercado?", realizado no Centro de Estudos Sociais em 27 e 28 de maio de 2011. Uma versão diferente da argumentação aqui apresentada foi publicada no Le Monde Diplomatique (edição portuguesa), de julho de 2011, sob o título "A saúde na crise: o que está em jogo".
} 
quatro décadas, o processo de emergência e consolidação do que tem sido designado por ordem neoliberal. ${ }^{1}$

A consolidação dessa ordem, através de um processo que constitui, porventura, um dos mais espetaculares exemplos de construção do que Antonio Gramsci chamou hegemonia, acabaria por levar a um assalto a alguns dos espaços que, aparentemente, pareciam escapar à lógica da procura do lucro e da coordenação pelo mercado. Habituámo-nos, durante décadas, a considerar a saúde - tal como a educação ou a segurança social - como um exemplo desses espaços. O rápido crescimento da despesa global com cuidados de saúde nos países do hemisfério norte apareceu como um dos primeiros pretextos para a afirmação da necessidade de o domínio da saúde passar, também, a ser gerido com um rigor que só o recurso ao mercado e aos seus mecanismos permitiria. Esse crescimento da despesa é indissociável das transformações que modificaram de maneira significativa e durável o perfil demográfico das populações desses países, em particular através do processo que os demógrafos descrevem como o envelhecimento da população - mais precisamente, o triplo processo de aumento dos efetivos das classes de idades mais avançadas associado ao aumento da esperança de vida, à redução dos efetivos das classes de idades mais jovens, decorrente do declínio da fecundidade, e ao aumento da longevidade dos mais idosos, por sua vez ligado à importância crescente das doenças crónicas e degenerativas. Mas ele decorre também dos sucessos da medicina moderna, da sua capacidade de prevenir e tratar doenças graves que, outrora, eram invariavelmente letais, transformando-as, em certos casos, em doenças curáveis e, noutros, em doenças crónicas que requerem cuidados continuados e dispendiosos nomeadamente sob a forma de medicamentos. Essa transformação, contudo, não ocorreu de maneira igual em todo o lado. Nos países do hemisfério sul, a maioria da população continua a estar exposta aos "grandes assassinos", que são doenças como a malária, a tuberculose ou a SIDA, assim como a uma longa lista de outras doenças, geralmente de origem infecciosa, que têm sido, significativamente, agrupadas sob a designação de doenças negligenciadas. Para várias destas doenças existem tratamentos eficazes - que muitas vezes permitem a cura - mas que não estão no entanto ao alcance da maioria da população mundial por esta não dispor de recursos para os adquirir. A razão para tal reside no facto de os peritos considerarem que esses tratamentos se caracterizam por uma diminuta relação entre os custos e a eficácia, o que leva a que não sejam facultados pelas autoridades de saúde

\footnotetext{
${ }^{1}$ Sobre esse processo, e para uma caracterização, ancorada na sua história, do que se entende por neoliberalismo, veja-se Mirowski e Plehwe (2009).
} 
ou por programas e iniciativas internacionais. Os efeitos dessas doenças são potenciados por aquilo que se conta também como algumas das suas causas mais importantes: a ausência de condições mínimas de sobrevivência, como o acesso a água potável, alimentação adequada, abrigo, rendimento mínimo, educação e ambiente saudável, em suma por um conjunto de condições que configuram situações de violência estrutural que atingem, sobretudo, as crianças, as mulheres, os idosos e outros grupos especialmente vulneráveis. A estas condições juntam-se as exigências ligadas às intervenções de organizações internacionais comprometidas com o credo neoliberal, como os programas de ajustamento estrutural impostos pelo Fundo Monetário Internacional e os condicionalismos ligados às intervenções do Banco Mundial, cujas primeiras vítimas são, invariavelmente, os sistemas ou programas de proteção social, de saúde e de educação. ${ }^{2}$

Nos países do Norte e, em particular, nos países que integram o espaço da União Europeia, a proteção da saúde através de sistemas públicos com acesso garantido a todos os cidadãos parecia, até há pouco tempo, ser uma conquista sólida e indiscutível. Apesar das diferenças na cobertura efetiva dos sistemas, nas formas de financiamento ou na qualidade dos serviços, a garantia, pelo Estado, da proteção dos cidadãos em situações de doença, incapacidade ou deficiência aparecia como parte do celebrado Modelo Social Europeu, apresentado ao resto do mundo como a demonstração da possibilidade de compatibilizar o crescimento económico no quadro de um sistema capitalista com elevados níveis de proteção social. Os Estados-Providência dos países da Europa Ocidental, e os seus sistemas públicos de saúde em particular, foram assim frequentemente tomados como modelos para iniciativas com a mesma ambição noutras partes do mundo. É certo que, ao longo das últimas quatro décadas, o Estado social e os serviços públicos de saúde, em particular, foram sendo alvo de tentativas de, em nome da sua racionalização e da necessidade de garantir a sua sustentabilidade, os subordinar à disciplina do New Public Management, as formas de gestão do Estado e dos serviços públicos inspirada em princípios e práticas seguidas no setor privado. Mas, em geral, foi considerável a capacidade de resistência do que aparece, sem dúvida, como uma das grandes conquistas da luta pela cidadania, especialmente pela cidadania económica e social, e pela democracia no século Xx. A situação, contudo, parece estar a mudar rapidamente, e

\footnotetext{
${ }^{2}$ Para uma elucidativa discussão da situação da saúde global, que explora as relações entre a biologia e a ecologia dos agentes patogénicos, a violência estrutural e as políticas de saúde, veja-se Farmer (2005). Para um estudo exemplar, histórico e etnográfico, da implementação de programas elaborados por organizações e fundações internacionais para a prevenção e combate ao HIV/SIDA na Costa do Marfim e Burkina Faso e dos seus efeitos, veja-se Nguyen (2010).
} 
o que eram, até agora, escaramuças dentro de um terreno delimitado pela aceitação, pelo menos explícita, da legitimidade do Estado Social e dos serviços públicos de saúde com carácter universal, está a dar lugar a um risco real de erosão desses serviços e à afirmação da necessidade e da urgência de "salvar" a proteção à saúde através do recurso a mecanismos de mercado e de uma defesa da superior eficiência da prestação privada de cuidados.

Não é ambição deste artigo oferecer uma análise detalhada deste processo. O seu objetivo é mais modesto. Trata-se de identificar e caracterizar a tensão entre dois modos de encarar os vínculos que ligam os cidadãos ao Estado, neste caso no acesso aos cuidados de saúde. Essa tensão não decorre de escolhas técnicas associadas à garantia de maior eficácia e eficiência do sistema de saúde e da prestação de cuidados; ela funda-se numa oposição política entre conceções distintas da saúde enquanto bem e do direito à saúde enquanto direito de cidadania e direito humano. Seguiremos de perto o debate tal como ele tem tomado forma em fóruns públicos, especialmente através de artigos de imprensa, de modo a tornar explícitos os recursos retóricos e as formas de argumentação que configuram as diferentes posições no debate. O exercício é necessária e assumidamente parcial, e não dispensa uma análise teórica e empírica, que ainda está por fazer, da economia política da saúde em Portugal e no espaço da União Europeia.

\section{A privatização dos sistemas públicos de saúde}

As transformações em curso dos sistemas públicos de saúde nos países do Norte são justificadas, em geral, pela necessidade e a urgência de reformar esses sistemas, para que possa ser garantida a sua continuidade perante novos e alegadamente inescapáveis constrangimentos financeiros, decorrentes eles próprios do processo de globalização. Para isso, são mobilizados, principalmente, três tipos de argumentos:

a) a proteção da saúde não é um bem público, e por isso os cuidados de saúde devem ser considerados como bens a que se deverá aceder segundo o princípio do utilizador-pagador, sendo o acesso gratuito reservado aos que não podem pagar (Amaral, 2011); ${ }^{3}$

b) a prestação de cuidados de saúde deve ser avaliada em termos da relação custo-benefício, sendo a eficiência uma preocupação central;

\footnotetext{
${ }^{3}$ Não é pacífica a definição do tipo de bem que é a saúde (um bem público, privado ou privilegiado) e do que significa tratar a saúde (ou a proteção da saúde) como um direito (subjetivo, coletivo ou difuso). Esse tema merece um tratamento separado, que não pode ser realizado aqui. É importante sublinhar, de momento, que essa definição não pode ser separada das opções políticas que estão em confronto em relação às formas de prestação de cuidados de saúde e à responsabilidade do Estado. Para uma discussão de alguns dos problemas envolvidos, veja-se Nunes (2009).
} 
c) a sustentabilidade (financeira) dos sistemas públicos de saúde depende de o Estado Social se tornar "inteligentemente seletivo", deixando de ser, de fato, um sistema baseado no acesso universal e gratuito (ibidem).

O diagnóstico sugere que os sistemas públicos carecem de eficiência quando são comparados com os sistemas privados de prestação de cuidados de saúde, e por isso seria necessário privatizá-los (no momento atual parcial e seletivamente) e, sobretudo, abrir o setor à iniciativa privada e/ou adotar critérios de gestão inspirados na lógica empresarial. O feito combinado destes dois tipos de dinâmicas será o de expor o setor da saúde e a prestação de cuidados de saúde a formas de coordenação baseadas no mercado e nos critérios e instrumentos de cálculo e de gestão associados a este. Essa abertura significa a emergência de algo bastante diferente da medicina liberal, que coabita com os sistemas públicos na maioria dos países onde estes existem, e que, em boa parte, se mantém graças aos convénios e aos acordos de prestação de cuidados financiados, integral ou parcialmente, pelos sistemas públicos. Essa privatização/empresarialização assume, de facto, outras formas, associadas, nomeadamente, aos processos seguintes:

a) a criação de unidades de saúde geralmente ligadas a grupos financeiros, organizadas segundo o modelo da bealth maintenance e do managed care, e ligados, em geral, à expansão dos seguros privados de saúde;

b) a privatização da gestão de unidades de saúde e, em particular, a de hospitais públicos;

c) a transformação de hospitais públicos em entidades públicas empresariais;

d) a divisão entre a função de financiamento (pelo Estado) e de prestação (privada) de cuidados de saúde;

e) e, finalmente, como tem vindo a acontecer em alguns municípios do Brasil, à "terceirização" ou subcontratação dos cuidados de saúde através da sua transferência para as chamadas "organizações sociais". ${ }^{4}$

O segundo tipo de argumento centra-se na alegada insustentabilidade dos sistemas públicos de saúde, fazendo depender a viabilização financeira destes da sua privatização parcial ou da criação de um sistema a "duas

\footnotetext{
${ }^{4}$ Este processo tem sido objeto de um debate muito vivo no Brasil, dada a heterogeneidade do que conta como organização social. Tendo acompanhado o debate, pude verificar que muitas das entidades designadas por organizações sociais são, de facto, entidades privadas que captam fundos públicos para a prestação de serviços - não só no campo da saúde - que se substituem, muitas vezes, à obrigação do Estado de garantir o acesso dos cidadãos a esses serviços, de forma universal. Essas organizações distinguem-se de organizações comunitárias, por exemplo, que trabalham em colaboração e complementaridade com o Sistema Único de Saúde. É corrente a opinião de que as organizações sociais correspondem, de facto, a uma retirada do Estado da prestação de serviços públicos fundamentais.
} 
velocidades", garantindo acesso (mínimo) a cuidados de saúde às pessoas de baixos rendimentos, e fazendo depender de pagamento o acesso a certos tipos de cuidados e de serviços, podendo esse pagamento realizar-se através de seguros ou planos privados de saúde. A ideia de que o acesso aos cuidados de saúde deve ser pago em função da situação económica dos utentes, e que assim seria possível orientar mais recursos públicos para os utentes com menores rendimentos, é apresentada pelos seus proponentes como uma medida justificada por uma preocupação de equidade e de justiça social. A ênfase crescente nos custos dos cuidados diferenciados e no uso de recursos tecnológicos ou de cirurgias de maior complexidade leva, contudo, a ocultar as crescentes carências de recursos para os cuidados básicos, que são, em geral, o ponto de entrada para o sistema público de saúde.

Os críticos das receitas neoliberais consideram que a aplicação destas resulta, invariavelmente, no desmantelamento ou, pelo menos, na acentuada degradação dos sistemas públicos de saúde. No Brasil, esse processo é sugestivamente designado por sucateamento: uma redução dos recursos públicos alocados ao sistema público, que comprometem e limitam tanto a capacidade deste de garantir o acesso adequado e atempado aos cuidados e de prestar alguns tipos de cuidados diferenciados envolvendo recursos mais onerosos - como, por exemplo, os que envolvem tecnologias avançadas de diagnóstico ou cirurgias de maior complexidade -, com o resultado, como seria de esperar, de uma degradação da qualidade dos serviços prestados. A fuga de utentes com mais recursos para o setor privado, por sua vez, é acompanhada, muitas vezes, do financiamento público, através de convenções, por exemplo, da prestação privada de cuidados, mas sem a garantia de que será cumprido o princípio da integralidade, ou seja, que qualquer cidadão terá garantido o acesso a todos os tipos de cuidados, básicos e diferenciados, seja qual for o tipo e gravidade do problema de saúde em causa. Deste modo, a menor qualidade e eficiência dos serviços públicos torna-se uma profecia autocumprida e uma "evidência" que legitima o discurso privatizador. O sistema público de saúde tenderá, assim, a tornar-se um sistema orientado para a assistência aos mais pobres. E, como dizia lapidarmente Sir William Beveridge, recordado como o principal responsável pela institucionalização do sistema nacional de saúde e do estado social britânicos, um sistema de saúde para pobres será sempre um sistema pobre. ${ }^{5}$

\footnotetext{
${ }^{5}$ Noutro lugar, propus o conceito de "regimes de saúde" para designar estas diferentes configurações de saberes, instituições, políticas e formas de subjetivação (Nunes, 2012).
} 


\section{Como mudar os termos do debate?}

O debate sobre o presente e o futuro dos sistemas públicos de saúde exige, certamente, um exame rigoroso da argumentação mobilizada pelos defensores da privatização e da submissão do setor da saúde à disciplina do mercado e, em particular, o confronto desses argumentos com o registo empírico. O que nos mostra o estudo sistemático e comparado da informação disponível sobre a situação da saúde em países com sistemas públicos de saúde e em países em que a prestação de cuidados de saúde é dominada pelo setor privado? Quais os efeitos a esperar dos processos de privatização crescente do setor da saúde em países que possuem sistemas públicos de saúde?

Este é, sem dúvida, um exercício que é urgente realizar, sendo que procuro, mais adiante, trazer uma contribuição, reconhecidamente modesta, nesse sentido. Mas é importante ir mais longe e começar a tornar explícito o que é silenciado neste debate, que tende a ser conduzido como se, como gostam de afirmar os partidários e compagnons de route do neoliberalismo, a eficácia e a sustentabilidade dos serviços públicos e, em particular, dos sistemas de saúde, fossem uma questão técnica.

A ideia de que a promoção simultânea da equidade e da eficiência na prestação de serviços de saúde só pode ser conseguida através da privatização da prestação de cuidados ou da adoção de formas de organização e gestão dos sistemas de saúde inspiradas na lógica do mercado e da empresa é inseparável da conceção da própria saúde como um mercado em expansão e como um setor da economia altamente lucrativo. A argumentação a favor da coordenação pelo mercado neste domínio, porém, tropeça em duas questões que são raramente identificadas de maneira clara e inequívoca nos muitos relatórios e publicações que pretendem demonstrar a superioridade da coordenação pelo mercado. A primeira dessas questões é a ausência de discussão sobre as modalidades e critérios de avaliação da eficácia dos sistemas de saúde e dos serviços de saúde - isto é, da capacidade destes de cumprir a sua missão. De facto, a discussão dos meios e da sua gestão tende a transformar-se num fim em si, evitando tratar o problema da missão e dos objetivos dos sistemas de saúde, e de como avaliar o cumprimento desses objetivos, em termos, por exemplo, da evolução de indicadores do estado de saúde da população ou do seu acesso a cuidados de saúde, da realização dos princípios da universalidade e da integralidade - do acesso de todos os cidadãos a cuidados básicos e diferenciados -, ou ainda do grau em que os utentes do serviço de saúde podem participar no governo deste. Esta questão suscita uma outra, a das opções no plano político e ético que permitem definir o que significa justiça, equidade e direito quando falamos de saúde. Os sistemas nacionais de saúde, tal como foram desenhados e 
construídos, na Europa Ocidental, nos anos que se seguiram à Segunda Guerra Mundial, assentam, em geral, no direito igual de acesso de todos os cidadãos aos cuidados de saúde - tanto aos cuidados básicos como aos cuidados diferenciados -, e na exigência de que as condições de acesso e a qualidade da prestação de cuidados sejam as mesmas para todos os cidadãos, independentemente de diferenças de classe, rendimento, sexo, raça, etnia ou orientação sexual. O financiamento desses sistemas assenta no princípio da redistribuição dos recursos públicos, resultantes de impostos ou contribuições específicas para um sistema ou subsistema, que deve garantir tratamento igual a todos os cidadãos, independentemente do seu rendimento ou da sua capacidade contributiva. $\mathrm{O}$ postulado neoliberal, hoje transformado em ortodoxia, de que deve ser aligeirada a carga fiscal dos detentores de maiores rendimentos - alegadamente a fim de não comprometer o investimento -, de que as receitas devem provir principalmente de impostos sobre o consumo - com efeitos escassos ou nulos no plano da distribuição equitativa do esforço fiscal -, e de que todos os serviços devem ser pagos, total ou parcialmente, por aqueles que os procuram, constitui uma rejeição dos princípios de solidariedade e de redistribuição. ${ }^{6}$ Mas ela demonstra também a dificuldade de compatibilizar esta visão com conceitos que hoje são centrais para uma compreensão ampla da saúde como dimensão crucial da avaliação do sucesso ou bem-estar das sociedades, ${ }^{7}$ como o de saúde da população - sobre o qual assentou a criação da moderna saúde pública - ou o de saúde coletiva, como é designada a conceção de saúde que configura, por exemplo, o Sistema Único de Saúde do Brasil, e que identifica como "sujeitos" da saúde - e não como alvos de intervenções assistenciais - diferentes tipos de coletivos, populações ou grupos que partilham problemas e vulnerabilidades comuns. ${ }^{8}$

A viabilidade financeira de um sistema público de saúde é considerada, nas visões de inspiração neoliberal, como dependente do crescimento da riqueza, sem considerar o modo como esta é redistribuída. Aliás, medidas destinadas a redistribuir a riqueza, nomeadamente através de sistemas fiscais progressivos e da prestação de serviços públicos, são invariavelmente denunciadas como interferências na dinâmica do crescimento, criando obstáculos a este e à criação de condições para uma prosperidade que, alegadamente, beneficiaria todos. A "percolação" dos efeitos do crescimento,

\footnotetext{
${ }^{6}$ Audier (2012) define, precisamente, como característica comum das diferentes correntes do neoliberalismo, a recusa de um princípio solidarístico de organização da sociedade.

7 Veja-se, para uma contribuição para esta reflexão, Evans e Lamont (2009).

${ }^{8}$ Sobre o conceito de saúde coletiva e as suas implicações nos planos cognitivo, político e institucional, veja-se Campos et al.(2007).
} 
da acumulação de capital e da concentração de riqueza garantiria, assim, que alguma parte dos resultados desse processo recaia sobre os mais pobres.

São, pois, opções políticas e éticas que delimitam o quadro a partir do qual se torna possível discutir o financiamento e a organização dos cuidados de saúde. Por outras palavras, termos como eficiência ou sustentabilidade fazem sentido apenas quando esse enquadramento político e ético é explicitado. O que está em causa, de facto, é o confronto entre conceções distintas e conflituais da economia política da saúde.

\section{Como avaliar o desempenho dos sistemas de saúde?}

Um exemplo particularmente interessante dos caminhos que poderia seguir o debate sobre a economia política da saúde se fosse assumido explicitamente o confronto entre opções no plano político e ético, permitindo lançar uma outra luz sobre os temas da eficiência e da sustentabilidade, é o que nos é oferecido por Robert Evans, um economista da saúde canadiano e uma das principais figuras associadas à construção de um serviço nacional de saúde nesse país. Em 2008, Evans publicou na revista Healthcare Policy um artigo que abordava, precisamente, o tema que aqui é tratado. $\mathrm{O}$ autor parte de uma reflexão sobre uma tese que, desde os anos 1970, tem sido bastante popular em algumas abordagens da história e da economia política da saúde. Essa tese, formulada pelo médico e historiador da medicina e da saúde pública Thomas McKeown (1979) e ilustrada pela história do declínio da tuberculose, é a de que, mais do que o acesso a cuidados médicos e a medidas de saúde pública, teriam sido o crescimento económico e as melhorias a ele associadas do nível de vida e de nutrição da população que permitiram os avanços mais significativos na erradicação ou controlo de doenças graves, de carácter endémico ou epidémico, assim como uma melhoria geral do estado de saúde das populações da Europa setentrional, entre os inícios do século XIX e as primeiras décadas do século XX. A conclusão que parecia impor-se era, pois, a de que o principal motor da melhoria das condições de saúde das populações seria a transformação das condições económicas gerais, associada ao crescimento. Daí que fosse grande a tentação, para muitos economistas, historiadores e outros cientistas sociais, de tratar o efeito do alargamento do acesso a cuidados de saúde quase como um epifenómeno do crescimento. Por outras palavras, para além de o acesso alargado ou universal a cuidados de saúde não ter o papel central que por vezes se lhe atribuía na melhoria da saúde das populações, esse acesso dependeria do crescimento como condição de disponibilização de recursos para financiar - no setor público ou no privado - cuidados de saúde para todos. Nessa perspetiva, o acesso a cuidados de saúde deveria 
estar positivamente associado a uma medida do crescimento e do estado da economia como o PIB per capita. ${ }^{9}$ Vale a pena, parenteticamente, observar que esta posição teve, como não é difícil de compreender, os seus defensores à direita e à esquerda, os primeiros insistindo no papel fundamental e insubstituível do crescimento económico e do aumento da riqueza global da sociedade como condição de maior saúde e bem-estar, os segundos acentuando a necessidade de transformações sociais e económicas capazes de garantir a redistribuição dos recursos gerados pelo crescimento - o próprio McKeown, aliás, incluía-se nestes últimos.

Esta tese, contudo, viria a tropeçar em dois casos que pareciam paradoxais quando eram examinados em termos comparados, ambos situados no continente americano. O primeiro é o dos Estados Unidos. Apesar de ser o país do mundo com o maior rendimento per capita, de ser aquele que dedica uma fração maior do seu PIB à saúde (globalmente e per capita, considerando o conjunto dos recursos privados e públicos) e de ser reconhecido, em geral, como o país onde se realiza a investigação mais avançada e de onde saem as inovações mais importantes no domínio da saúde, os Estados Unidos apresentam valores para indicadores de saúde que são geralmente utilizados em comparações internacionais - como a mortalidade até aos cinco anos ou o acesso da população a cuidados de saúde - piores do que o de países do mesmo continente com um PIB per capita significativamente inferior.

O segundo caso é o de Cuba. Com um PIB per capita de cerca de um décimo do dos Estados Unidos, Cuba apresenta indicadores como a esperança de vida ao nascimento com valores idênticos aos dos Estados Unidos, sendo esse valor ultrapassado apenas pelo Canadá; a taxa de mortalidade até aos cinco anos é inferior à dos Estados Unidos (ultrapassada apenas, no continente, pela do Canadá, mais uma vez); e o número de médicos por mil habitantes mais elevado do continente. ${ }^{10} \mathrm{~A}$ comparação da situação dos Estados Unidos com a do Canadá é igualmente significativa. O PIB per capita do Canadá é ligeiramente inferior ao dos Estados Unidos, mas o desempenho em todos os principais indicadores de saúde é superior.

As comparações dos indicadores referidos obrigam a, pelo menos, matizar a tese de McKeown, limitando as condições da sua validade. Como mostra

\footnotetext{
${ }^{9}$ Para uma discussão crítica e detalhada das teses de McKeown, veja-se Szreter (2002).

${ }^{10}$ O estudo antropológico de Brotherton (2012) sobre a saúde em Cuba após a dissolução da União Soviética mostra que, se a orientação da política pública de saúde teve uma importância fundamental para a qualidade da saúde da população cubana, é importante considerar também a forma como os responsáveis políticos, agentes do sistema de saúde e cidadãos foram respondendo, de forma criativa e flexível, a situações de grandes dificuldades no acesso a recursos necessários ao funcionamento do próprio sistema de saúde, como sucedeu, por exemplo, no chamado "Período Especial", após o desaparecimento da União Soviética.
} 
Evans, recorrendo a dados da Organização Mundial de Saúde, a associação entre a esperança de vida ao nascimento e o PIB per capita tende a ser forte para países com PIB per capita baixo - ou seja, o crescimento do PIB tende a favorecer, nesses casos, o aumento da esperança de vida -, mas essa associação deixa de ser significativa a partir de um certo limiar, ou seja, um certo valor do PIB per capita. Esta observação leva Evans a interrogar-se sobre a influência do acesso a cuidados de saúde nas condições de saúde da população, uma vez atingido esse limiar. Para Evans, a importância de um sistema público de saúde próximo da população, dando prioridade aos cuidados primários de saúde, com médicos investidos de funções que têm a ver não apenas com intervenções médicas, mas também com o que designa de "determinantes não-médicos da saúde", permite um desempenho superior do sistema de saúde. Esse desempenho não depende apenas do volume de recursos alocados ao sector da saúde, mas de uma opção política (que pode assumir formas distintas em regimes políticos diferentes) a favor da saúde da população e da priorização do que tem sido descrito como "Community-Oriented Primary Care" (Evans, 2008: 31).

A comparação entre os Estados Unidos, Canadá e Cuba permite, assim, a Evans avançar que a existência de um sistema público de prestação de cuidados de saúde, como ele existe, embora com diferenças, no Canadá e em Cuba, é fundamental para a melhoria dos indicadores de saúde, e que, se for invocado o critério da eficiência, tanto o Canadá como Cuba obtêm resultados significativamente superiores aos dos Estados Unidos em matéria de utilização de recursos para a saúde, com um volume menor de recursos. Ou seja, contrariamente às alegações dos defensores da privatização e do mercado, a prestação de cuidados de saúde através de sistemas públicos parece ser mais eficaz - os resultados em termos de indicadores do estado de saúde da população são superiores - e mais eficiente - um menor volume de recursos, global e per capita, produz melhores resultados - do que a prestação através do mercado e de serviços privados... Em suma, um serviço público de saúde, que garanta o acesso a cuidados a todos os cidadãos, independentemente dos seus rendimentos, parece fazer uma diferença considerável no desempenho de uma sociedade em matéria de indicadores de saúde.

A sustentabilidade de um sistema público de saúde não pode ser discutida sem referência às escolhas políticas que estão na base do privilégio concedido à prestação pública ou privada de cuidados de saúde. Ela não decorre de um imperativo técnico, que seria independente dessas escolhas. As propostas de reforma dos serviços nacionais de saúde na Europa, fortemente marcadas pela tentação de ampliar o espaço da saúde como um setor económico 
altamente lucrativo e submetido à lógica do mercado e a instrumentos de coordenação e regulação associados a este, afirmando ao mesmo tempo o compromisso com um sistema público reduzido, reformado, com uma forte orientação assistencial para aqueles que não podem pagar, configuram, de facto, opções políticas de compatibilidade mais do que duvidosa com a definição constitucional do direito à proteção da saúde e da obrigação da sua garantia através de um sistema público, universal e acessível a todos os cidadãos. A legitimação desse projeto depende do que pode ser descrito como a ocultação efetiva do registo histórico e contemporâneo do desempenho comparado dos sistemas de saúde e, em particular, da diferença associada à existência de sistemas públicos.

Não quer isto dizer que, quer no plano da organização e da gestão dos sistemas públicos de saúde, quer no das modalidades do seu financiamento, não seja necessário e urgente um debate que mobilize e avalie as experiências internacionais neste domínio, e que procure encontrar soluções inovadoras para os problemas que o próprio crescimento e sucesso dos sistemas públicos de saúde não deixaram de gerar. Mas esse debate deve ser inequivocamente situado no debate mais amplo sobre as opções políticas no domínio da saúde.

\section{A saúde em Portugal na era "pós-Troika"}

Em Portugal, a questão (recorrente) do presente e do futuro do Serviço Nacional de Saúde (SNS) e, em particular, da sua sustentabilidade e da indispensabilidade da sua reforma assume um lugar de particular relevo em tempos de crise. Habituámo-nos a ouvir tratá-la como um problema técnico, que seria resolvido através de um exame rigoroso da situação recorrendo aos instrumentos da economia e a uma apreciação lúcida dos constrangimentos decorrentes da globalização. E sempre, claro, tendo no horizonte a preocupação de reformar o sistema para que possa continuar a ser garantido o acesso dos cidadãos a este. ${ }^{11}$ Essas posições têm merecido respostas públicas que contribuem para abrir um espaço de crítica e de debate sobre os futuros possíveis do SNS. ${ }^{12}$

Note-se que foi nos países do Sul que, pela mão de organizações internacionais, foram experimentadas, como parte de um "ajustamento estrutural" - que incluía, invariavelmente, o "emagrecimento" forçado de todos os serviços públicos, incluindo a saúde -, as políticas que, agora, são postuladas para os países do Norte. Estas são orientadas para a liberalização e a

\footnotetext{
${ }_{11}$ Veja-se, por exemplo, o artigo citado de Mira Amaral no jornal Público de 8 de maio de 2011.

12 Veja-se, a título de exemplo, as contribuições de Sandra Monteiro, de Isabel do Carmo e do autor deste artigo que integram o dossiê incluído na edição de julho de 2011 do jornal Le Monde Diplomatique (edição portuguesa).
} 
privatização (anunciada, geralmente, como parcial e seletiva) de domínios como a segurança social, a educação ou a prestação de cuidados de saúde, que, mesmo quando financiados pelo Estado, passam a estar associados a uma ampliação da oferta privada e ao estímulo à concorrência.

Por sua vez, a ideia de que o acesso aos cuidados de saúde deve ser pago em função da condição económica dos utentes, e que assim seria possível orientar mais recursos públicos para os utentes com menores rendimentos, é apresentada, frequentemente, como uma medida justificada por uma preocupação de equidade e de justiça social. A ela está associada a criação de mecanismos de "moderação" (como as taxas moderadoras) do acesso a serviços públicos, a fim de desincentivar os "abusos" ou usos indevidos ou injustificados destes. É interessante notar que a figura do "abuso", que justificaria a aplicação de medidas capazes de "moderar" o acesso aos cuidados de saúde, parece só existir para aqueles que necessitam de recorrer aos serviços públicos. O acesso frequente a cuidados de saúde no setor privado por aqueles que dispõem dos recursos para os pagar, mesmo em casos que seriam considerados "injustificados" (por razões clínicas ou de poupança e racionalização de recursos) no setor público, parecem, pelo contrário, ter a consequência virtuosa de aumentar o volume de negócios quando ocorre no setor privado. Assim vai a "seletividade inteligente"...

De facto, e como também já foi lembrado, este tipo de medidas resulta, em geral, no efetivo desmantelamento ou, pelo menos, na acentuada degradação dos sistemas públicos de saúde, reduzindo os recursos a eles alocados e comprometendo tanto a sua capacidade de garantir o acesso aos cuidados inscrito na Constituição da República como um direito de todos os cidadãos como a prestação de cuidados diferenciados e a própria qualidade dos serviços prestados. A fuga das pessoas com mais recursos para o setor privado, por sua vez, assume muitas vezes a forma de financiamento público da prestação privada de cuidados. Desse modo, a menor qualidade e eficiência dos serviços públicos torna-se uma profecia autocumprida e uma "evidência" que legitima o discurso privatizador. O sistema de saúde público tende, assim, a tornar-se não só um sistema orientado para a assistência aos mais pobres mas também cada vez mais pobre em recursos.

São as opções políticas e éticas que delimitam o quadro a partir do qual se torna possível discutir como financiar e como organizar de modo eficiente a prestação de cuidados de saúde. Por outras palavras, termos como racionalização, eficiência ou sustentabilidade fazem sentido apenas quando esse enquadramento político e ético é explicitado. O que está em causa é o confronto entre conceções distintas da economia política da saúde, que não dispensa, evidentemente, uma discussão séria sobre as alternativas de 
financiamento do Serviço Nacional de Saúde e, em particular, aquelas que assentam em medidas fiscais progressivas, em lugar das medidas regressivas que são hoje preconizadas e que penalizam desproporcionadamente aqueles que têm menos rendimentos.

O recente Relatório de Primavera do Observatório Português dos Sistemas de Saúde (OPSS) de 2011 oferece elementos importantes para compreender o que está em jogo na saúde perante as condições impostas ao Estado português pelo acordo explicitado no Memorando de Entendimento acordado pela chamada "Troika", constituída pelo FMI, pelo Banco Central Europeu e pela União Europeia, com os três partidos políticos que têm ocupado o poder em Portugal nos últimos trinta anos..$^{13} \mathrm{~A}$ partir de uma análise minuciosa das medidas propostas para o setor da saúde nesse Memorando, o Relatório do OPSS propõe dois cenários que delimitam o espaço dos cenários possíveis de intervenção no setor, em função de evoluções possíveis dentro do espaço definido pelos termos do Memorando. ${ }^{14}$ São delineadas, assim, duas grandes direções possíveis para a política de saúde: a primeira é a da crise como oportunidade, entendendo-se esta como a oportunidade de mobilização das forças e das capacidades que permitam consolidar um sistema baseado na solidariedade e na equidade e na garantia de proteção adequada na saúde aos mais vulneráveis; a segunda é a de "pagar cada vez mais por cada vez menos", que corresponde, de facto, à erosão progressiva do sistema público de saúde. Embora, como se afirma no Relatório, seja possível estar de acordo com muitas das medidas enunciadas no Memorando, é importante sublinhar que o sentido da sua aplicação será diferente consoante o cenário, ou, por outras palavras, consoante a opção política seja a de reforçar um sistema público que garanta o acesso à saúde a todos os cidadãos em condições de equidade ou a de dar prioridade à redução do investimento público no sistema e promover a privatização e liberalização do setor. A formulação destes dois cenários permite que o Relatório deixe em aberto o rumo que poderá tomar a política de saúde em Portugal nos próximos anos. Contudo, uma leitura atenta das medidas preconizadas no Memorando, assim como uma consideração lúcida da relação de forças na sociedade portuguesa e das condições políticas atuais, sugerem que o segundo cenário - ou, quando muito, um cenário intermédio próximo deste) será, se nenhuma mudança substancial ocorrer, o mais plausível. Esta sugestão é respaldada

\footnotetext{
${ }_{13}$ Veja-se, ainda, sobre este tema, as contribuições ao já referido dossiê de Le Monde Diplomatique (Carmo, 2011; Monteiro, 2011; Nunes, 2011).

${ }^{14}$ Observatório Português dos Sistemas de Saúde, 2011. Estes cenários balizam, de facto, o espaço dos cenários possíveis, admitindo-se como plausíveis outros cenários intermédios, que se aproximem mais de um ou de outro dos cenários propostos.
} 
pelas prioridades enunciadas pelo atual Primeiro-Ministro de Portugal, nomeadamente a da subordinação de todas as políticas públicas ao objetivo da consolidação orçamental. Mas é importante sublinhar que as medidas elencadas no Memorando para o setor da saúde estão longe de ser um conjunto disperso de medidas destinadas a favorecer a consolidação orçamental. No seu todo, elas podem ser lidas como a formulação de uma estratégia deliberada de desmantelamento de facto do Sistema Nacional de Saúde tal como o conhecemos e de privatização do setor. É significativo que, num país onde a percentagem de gastos privados nos gastos totais com saúde são já extremamente elevados (22 a 23\%, quando a Organização Mundial de Saúde recomenda um máximo de $15 \%$, sob risco de se entrar numa "espiral catastrófica”...), se postule que o sistema seja cofinanciado através de taxas moderadoras, e que estas tenham sofrido aumentos significativos nos últimos meses; ou que não haja qualquer menção à necessidade, em plena depressão, de medidas de proteção dos setores mais pobres e vulneráveis. ${ }^{15}$

O caminho apontado pelo cenário que, neste momento, parece o mais plausível é o da manutenção formal de um Serviço Nacional de Saúde, mas um SNS subfinanciado pelo Estado, com a gestão das unidades de saúde entregue a entidades privadas ou sujeita à lógica da empresa, com uma clara segmentação entre os utentes que podem contribuir - e que poderão optar pela prestação de cuidados no setor público ou no privado - e os que, sem os recursos que tornem possível essa opção, passam de cidadãos a dependentes de práticas assistenciais, sem outra alternativa senão a de recorrer a um serviço público que, concebido como universal, passa a ser um serviço para os pobres.

\section{Os mercados fazem bem à saúde?}

A ideia de que a privatização e a prestação de serviços de saúde através de organizações submetidas à lógica da empresa e do mercado permitem uma prestação mais eficiente e mais adequada de cuidados de saúde mereceu já, como foi aqui lembrado, a atenção de investigadores que procuraram pôr à prova esse postulado através de análises comparativas, recorrendo a informação disponibilizada por organizações internacionais, como a Organização Mundial de Saúde. Apesar da acessibilidade dessa informação, ela é ignorada nas intervenções públicas de responsáveis governamentais e de defensores das reformas de inspiração neoliberal insiste na "necessidade" e na "indispensabilidade" dessas reformas (sempre em nome da necessidade

${ }_{15}$ Observatório Português dos Sistemas de Saúde, $(2011:$ 62, 77, 78). 
de, perante novas condições, geralmente justificadas pela força imparável da globalização, "salvar" os sistemas públicos de saúde...).

Os sistemas públicos de saúde têm sido, nas décadas posteriores à Segunda Guerra Mundial, um dos principais pilares do que ficou conhecido como o Modelo Social Europeu, que o tornou um modelo atraente para a organização de uma sociedade solidária noutras partes do mundo; em Portugal, o SNS continua a ser considerado pelos cidadãos como uma das conquistas mais significativas do regime democrático. As repetidas declarações sobre a falência ou inadequação do modelo social europeu e da proteção da saúde que ele garantia estão aí para nos lembrar que o projeto de uma Europa dos cidadãos - e a própria afirmação política da Europa no mundo - continua a ter como uma das suas bandeiras mais importantes a defesa, ampliação e consolidação de padrões elevados de proteção social, incluindo a proteção da saúde.

Por isso é urgente a revitalização de um debate público que reafirme a vitalidade da economia política da saúde.

\section{Referências bibliográficas}

Amaral, Luís Mira (2011), "O futuro do Estado Social: o caso da saúde", Público, 8 de maio.

Audier, Serge (2012), Néolibéralisme(s): une archéologie intelellectuelle. Paris: Grasset. Brotherton, P. Sean (2012), Revolutionary Medicine: Health and the Body in Post-Soviet Cuba. Durham, North Carolina: Duke University Press.

Campos, Gastão Wagner de Souza; Minayo, Maria Cecília de Souza; Akerman, Marco; Drumond Júnior, Marcos; Carvalho, Yana Maria de (orgs.) (2007), Tratado de saúde coletiva. Rio de Janeiro/São Paulo: Editora Fiocruz/HUCITEC.

Carmo, Isabel do (2011), "A Troika, o memorando e os serviços de saúde”, Le Monde Diplomatique, julho.

Evans, Peter; Lamont, Michèle (orgs.) (2009), Successful Societies: How Institutions and Culture Affect Health. Cambridge: Cambridge University Press.

Evans, Robert G. (2008), "Thomas McKeown, Meet Fidel Castro: Physicians, Population Health and the Cuban Paradox", Health Care Policy, 3(4), 21-32.

Farmer, Paul (2005), Pathologies of Power: Health, Human Rights, and the New War on the Poor. Berkeley: University of California Press.

McKeown, Thomas (1979), The Role of Medicine: Dream, Mirage or Nemesis? Oxford: Basil Blackwell [2. ${ }^{a}$ edição].

Mirowski, Philip; Plehwe, Dieter (orgs.) (2009), The Road from Mont Pélerin: The Making of the Neolibeal Thought Collective. Cambridge, Massachusetts: Harvard University Press. 
Monteiro, Sandra (2011), “A destruição programada do SNS”, Le Monde Diplomatique, julho.

Nguyen, Vinh-Kim (2010), The Republic of Therapy: Triage and Sovereignty in West Africa's Time of AIDS. Durham, North carolina: Duke University Press.

Nunes, João Arriscado (2009), "Saúde, direito à saúde e justiça sanitária”, Revista Crítica de Ciências Sociais, 87, 143-169.

Nunes, João Arriscado (2011), “A saúde na crise: o que está em jogo”, Le Monde Diplomatique, julho.

Nunes, João Arriscado (2012), "Embodied Expectations: The Somatic Subject and the Changing Political Economy of Life and Health", in José Castro Caldas e Vítor Neves (orgs.), Facts, Values and Objectivity in Economics. London: Routledge.

Observatório Português dos Sistemas de Saúde (2011), Relatório da Primavera 2011. Coimbra: OPSS/INODES/FCG.

Szreter, Simon (2002), "Rethinking McKeown: The Relationship between Public Health and Social Change”, American Journal of Public Health, 92(5), 722-725. 